\title{
Impact of Illness Perception on the Health- Related Quality of Life of Patients Receiving Dialysis: A Cross-Sectional Study
}

Abdulhameed A. Alharbi ${ }^{1}$, Yazeed A. Alharbi ${ }^{2}$, Ahmed S. Alsobhi ${ }^{3}$, Mohammad A. Alharbi ${ }^{4}$, Mariam A. Alharbi ${ }^{4}$, Adwaa A. Aljohani ${ }^{5}$, Alwaleed A. Alharbi ${ }^{1}$

1. Joint Program of Preventive Medicine Post Graduate Studies, Ministry of Health, Medina, SAU 2. Department of Internal Medicine, King Fahad Hospital, Jeddah, SAU 3. Department of Internal Medicine, King Abdulaziz University Hospital, Jeddah, SAU 4. Faculty of Medicine, King Abdulaziz University, Jeddah, SAU 5. Health Affairs, Ministry of Health, Medina, SAU

Corresponding author: Abdulhameed A. Alharbi, aaalsobhi@hotmail.com

\section{Abstract}

\section{Background}

End-stage renal disease (ESRD) is a major health problem worldwide that is increasing in incidence, prevalence, and cost. Both the disease itself and negative illness perceptions negatively affect patients' health-related quality of life (HRQoL), morbidity, and mortality. This study assessed the relationship between illness perception and HRQoL.

\section{Methods}

This cross-sectional study was conducted among 342 patients at five dialysis centers in Jeddah, Saudi Arabia. We used a self-administered questionnaire that containing demographic questions, the Revised Illness Perception Questionnaire, and the Short Form 36 Health Survey Questionnaire. The data were analyzed using t-tests, analyses of variance, Pearson's correlation coefficients, and multiple linear regression analyses.

\section{Results}

The mean (SD) age was 46.1 (16.5) years and the majority were men (53.8\%). Except for treatment control, all domains of illness perception were significantly correlated with HRQoL; however, the correlations were positive only for personal control and illness coherence. Identity, disease timeline (acute/chronic), consequences, illness coherence, and emotional representations were independent predictors of HRQoL; together explaining $35 \%$ of the variance. Lower emotional response was the only domain of illness perception significantly associated with better HRQoL in both dialysis modalities across all dialysis centers.

Review began 06/02/2021 Review ended 06/08/2021 Published 06/17/2021

() Copyright 2021 Alharbi et al. This is an open access article distributed under the terms of the Creative Commons Attribution License CC-BY 4.0., which permits unrestricted use, distribution, and reproduction in any medium, provided the original author and source are credited.

\section{Conclusion}

There were clear effects of illness perception on HRQoL, with emotional representations being the strongest predictor. As such, emotional representations should be targeted in interventions.

Categories: Preventive Medicine, Urology, Epidemiology/Public Health

Keywords: dialysis, end-stage renal disease, health-related quality of life, illness perception, saudi arabia

\section{Introduction}

End-stage renal disease (ESRD) is a major health problem worldwide that is increasing in incidence, prevalence, and cost [1-2]. ESRD is a debilitating, chronic condition that requires medical interventions, such as dialysis and some lifestyle, dietary, and fluid restrictions, for effective management [3-4]. For patients with ESRD, the blood-filtering function of the kidneys can be replaced by a medical procedure: dialysis [4-5].

The burden of illness among patients requiring dialysis can be aggravated by many factors such as treatmentrelated issues, limited activities, financial difficulties, and marital status stability. All these factors might increase emotional distress and affect the psychosocial wellbeing of the patients [5-6]. Patients with ESRD have a propensity to have a specific pattern of beliefs about their illness that can figure in their illness perception and the way they respond to it [4].

The illness perception of patients with a chronic disease is best described by the Self-regulatory Model (SRM) $[5,7]$. This model suggests that when a change in physical health takes place, individuals interpret their symptoms and create a hypothesis about their illness [8]. Accordingly, patients' clinical outcomes and the 
ways of coping or controlling the symptoms is highly affected by the characteristics of an individual's illness representation and beliefs about the illness and its treatment [8-11].

Patients' adaptive or maladaptive responses to an illness can be understood by identifying such beliefs and, consequently, improving adaptive functioning by altering such perceptions [5].

Health-related quality of life (HRQoL) is a key outcome indicator in research on patients with chronic illnesses, particularly in assessing the effects of different treatment modalities, including various forms of renal replacement therapy [12-13]. HRQoL generally serves as an indicator of patients' wellbeing; however, it is also related to important clinical outcomes such as death [14].

The HRQoL of patients with chronic diseases, including ESRD, has been of particular interest [15]. ESRD, or indeed any chronic disease in combination with negative illness perceptions, can negatively affect patients' HRQoL, which can affect morbidity and mortality $[5,11]$. This has received some empirical support: poor HRQoL is strongly related to an increased risk of mortality among patients on dialysis $[14,16]$.

Illness perception correlates differently with each of the eight domains of HRQoL: physical functioning, bodily pain, role-physical, role-emotional, emotional wellbeing, social functioning, energy/fatigue (vitality), and general health. Specifically, certain domains of illness perception are inversely correlated with HRQoL while others are positively correlated, as related below. Furthermore, the variance in HRQoL might be explained by only some of the domains of illness perception $[5,17-18]$.

In a longitudinal study in the Netherlands, illness perception explained about $17 \%$ of the variance in the bodily pain and role-emotional domains of HRQoL and up to $51 \%$ of the variance in the mental health domain. Furthermore, each domain of HRQoL was explained by a different set of illness perception domains. Illness identity showed significant negative contributions to most domains of HRQoL. Consequences and emotional representations, however, showed strong negative associations with some of the domains [5]. Another three cross-sectional studies in Romania, Malaysia, and Iran, found that illness perception explained between $15 \%$ and $34 \%$ of the variance in the domains of HRQoL [17-18].

Over the last three decades, there has been a marked rise in the incidence and prevalence of ESRD in the kingdom of Saudi Arabia [19-20]. At the present rate, the number of patients with ESRD exceeds 20,000 [21]. Exploration of patients' illness perceptions and the effects of these perceptions on their HRQoL could help physicians tailor treatment plans to improve patients' HRQoL. However, there is a dearth of studies on the illness perception of ESRD among patients receiving dialysis in Saudi Arabia or the effects of such perception on patients' HRQoL. The aim of this study was to investigate the relationship between the HRQoL of dialysis patients and their illness perceptions.

\section{Materials And Methods \\ Study setting and study population}

This cross-sectional study was conducted at five dialysis centers in Jeddah city, Saudi Arabia. The inclusion criteria were having stable health (i.e., the ability to complete questionnaires), aged > 18 years, and having at least three or more months of dialysis. Patients who had a psychiatric disease were excluded.

\section{Sampling}

Proportionate stratification was used. First, we stratified participants by treatment modality, forming hemodialysis (HD) and peritoneal dialysis (PD) strata. Then, proportionate sampling was performed within each stratum. The calculated sample size was $(n=416)$. The equation used to calculate sample size was as follows: $n=z^{2} p(1-p) / \delta 2$, where $n=$ sample size, $z=z$ score (i.e., 1.96 for a $95 \%$ confidence level), $p=$ proportion, and $\delta=$ confidence interval (which reflects precision). The assumed proportion was set at 0.5 to obtain the maximal sample size while the worst acceptable value (ס) was set at 0.05 . This resulted in a sample size for an infinite population of 384 . To adjust the sample for a finite population, the sample size for each stratum was calculated using the following equation: $n_{i}=n_{0}\left(1+\left(n_{0}-1\right) / N\right)$, where $n_{i}=$ stratum sample, $n_{\circ}=$ calculated sample size for an infinite population, and $\mathrm{N}=$ stratum population. At each dialysis center, patients at each dialysis session were sorted alphabetically in tables to ensure homogeneity. Then, using simple random sampling, participants were selected according to the sample size of each stratum at each dialysis center.

\section{Study instruments}

Together with socio-demographic data, two self-administered questionnaires were provided to participants: the Revised Illness Perception Questionnaire (IPQ-R) [22] and the Short Form 36 Health Survey Questionnaire (SF-36) [23], which were integrated into a single questionnaire package in Arabic. The part of the questionnaire on demographic information was preceded by an introduction requesting for patients to fill in the questionnaire during their dialysis sessions, without compensation, and to include their participation agreement and personal data. The socio-demographic data $r$ included age, sex, educational 
level, marital status, and employment status. The second part of the questionnaire contained the wellvalidated IPQ-R. Currently, the IPQ-R is the most common instrument used among patients with chronic diseases for the assessment of illness perceptions [24]. It is an 84-item instrument that assesses the different domains of illness perception. It has three parts and nine subscales [25].

The first part includes one subscale, identity, that is used to assess the symptoms associated with patients' condition. Patients were asked about 14 symptoms and if they thought that symptoms were related to their illness. The number of yes-rated items forms the score of the identity subscale [25-26].

The second part includes 38 items, which are divided into seven subscales: timeline acute/chronic, timeline cyclical, consequences, personal control, treatment control, illness coherence, and emotional representations. Each item was rated on a five-point Likert scale, ranging from 1 ("strongly disagree”) to 5 ("strongly agree"). The overall score was obtained by the sum of the items of each subscale. The scores of 13 items out of 38 , were reversed [25].

High scores on the consequences, emotional representations, and timeline subscales indicate a more negative perception of the illness [27]. That means that patients view the illness as chronic and cyclical in nature and believe their illness to be serious outcomes and they have strong emotional reactions to it. Each item was rated on a five-point Likert scale, ranging from 1 ("strongly disagree") to 5 ("strongly agree”). More positive perceptions about the controllability and understanding of the illness is indicated by high scores on the treatment control, personal control, and coherence subscales [27].

The third section includes one subscale, the causal subscale, which is concerned with 18 possible causes that might be attributed by patients to their current illness. The mean of each item is computed, and a higher mean indicated a more common cause [27].

Forward-backward translation by two experts was used to translate the IPQ-R into the Arabic language.

The final part of the study questionnaire was the Arabic version of the SF-36. This is a widely used validated instrument for assessing HRQoL [23]. The SF-36 assesses eight domains of HRQoL: physical functioning, bodily pain, role-physical, role-emotional, emotional wellbeing, social functioning, energy/fatigue (vitality), and general health. Of the 36 items, one item assesses the change in general health over a one-year period [28]. The Cronbach's alphas for the Arabic RAND-36 in multiple subgroups exceeded 0.70 for every scale except general health (Cronbach's alpha $=0.59)[28]$.

The SF-36 is scored using a two-step process. First, all items are scored according to a given key. The Likert score of each item is then transformed to a range from 0 to 100. In step two, items in the same subscale are average together to create subscale scores. Items that are left blank are not considered when calculating the subscale scores. Therefore, each subscale score represents the mean of possible scores achieved in that subscale. The Arabic validated version of the SF-36 was used in this study.

\section{Procedure}

The study purpose and instructions about filling the questionnaire were explained to the participants. For illiterate participants, the data was collected through a face-to-face interview.

\section{Ethical considerations}

Permission for translating to Arabic and using the validated questionnaires was obtained from the original developer of the IPQ-R, Professor Rona Moss-Morris [22]. RAND Corporation, based in California, USA, allows anyone to use the SF-36, and it has been translated into a number of languages, including Arabic [29].

Ethical approval was obtained from each center. Participants were informed that participation was optional and that they could refrain from answering any question or the whole questionnaire if they so desired. Furthermore, participants were informed that information are confidential and would not be disclosed except for research purposes.

\section{Statistical analyses}

IBM SPSS software Version 20 (IBM Corp., Armonk, NY) was used for data analysis. Mean, SD, frequencies, and percentages were obtained in descriptive analysis. Pearson's correlations were calculated between the various subscales of the IPQ-R and SF-36. A backward multiple linear regression analysis was conducted (unlike forward stepwise analysis, it begins with the full least squares model containing all predictors, and then consecutively removes the least useful predictors) to determine the independent predictors of HRQoL. Variables that were not correlated with HRQoL in the correlational analysis were excluded as predictors from the regression analysis. Significance was set at $\mathrm{P} \leqslant .05$. The basic assumptions for performing regression analyses (i.e., assumptions of normal distribution, a linear relationship between the independent and dependent variables, reliability, and homoscedasticity) were met [30]. 


\section{Cureus}

\section{Results}

\section{Participants' characteristics}

The overall response rate was $82.2 \%$. The majority were men (53.8\%), single (56.1\%), and unemployed (74.2\%). The mean (SD) age was 46.2 (16.4) years (Table 1).

\begin{tabular}{|c|c|c|}
\hline Characteristic & $\mathbf{n}$ & $\%$ \\
\hline \multicolumn{3}{|l|}{ Sex } \\
\hline Male & 184 & 53.8 \\
\hline Female & 158 & 46.2 \\
\hline \multicolumn{3}{|l|}{ Marital status } \\
\hline Married & 96 & 28.3 \\
\hline Single & 190 & 56.1 \\
\hline Divorced & 19 & 5.6 \\
\hline Widowed & 34 & 10 \\
\hline \multicolumn{3}{|l|}{ Education level } \\
\hline Illiterate & 76 & 22.5 \\
\hline Just read and write & 21 & 6.2 \\
\hline Primary school & 43 & 12.7 \\
\hline Intermediate school & 46 & 13.6 \\
\hline High school & 86 & 25.4 \\
\hline Bachelor's degree or higher & 66 & 19.5 \\
\hline Age (Mean \pm SD) & \multicolumn{2}{|c|}{$46.1 \pm 16.5$ years } \\
\hline \multicolumn{3}{|l|}{ Occupation } \\
\hline Unemployed & 219 & 74.2 \\
\hline Employed & 76 & 25.8 \\
\hline
\end{tabular}

TABLE 1: Personal and professional characteristics of the participants

\section{Illness perceptions scores}

Regarding the IPQ-R score, the mean (SD) timeline cyclical was 3.42 (0.72), mean (SD) consequences was 3.36 (0.79), and mean (SD) illness coherence was 3.35 (0.80). This means that participants perceived their symptoms as changing over time, that their disease had an impact on their life, and that they perceive their conditions well. The mean (SD) personal control subscale was 3.24 (0.52), mean (SD) treatment control subscale was 3.32(0.49), and mean (SD) emotional representation subscale was 3.28 (1.0). The mean (SD) timeline acute/chronic score was 3.03 (0.79), which indicates that perceived their illness as chronic (Table 2). 


\section{Cureus}

\begin{tabular}{|c|c|c|c|c|}
\hline Subscale & Items mean (SD) & Score range & Mean (SD) & $\%$ \\
\hline Identity & & $\theta-14$ & $6.90(3.29)$ & $49.3 \%$ \\
\hline Timeline acute/chronic & $3.03(0.79)$ & $6-30$ & $18.2(4.77)$ & $60.7 \%$ \\
\hline Timeline cyclical & $3.42(0.72)$ & 420 & $13.7(2.87)$ & $68.5 \%$ \\
\hline Consequences & $3.36(0.79)$ & $6-30$ & $20.2(4.71)$ & $67.3 \%$ \\
\hline Personal control & $3.24(0.52)$ & $6-30$ & $19.5(3.14)$ & $64.9 \%$ \\
\hline Treatment control & $3.32(0.49)$ & $5-25$ & $16.6(2.43)$ & $66.5 \%$ \\
\hline Illness coherence & $3.35(0.80)$ & $5-25$ & 16.7 (3.99) & $67.0 \%$ \\
\hline Emotional representation & $3.28(1.00)$ & $6-30$ & $19.7(6.02)$ & $65.6 \%$ \\
\hline
\end{tabular}

TABLE 2: Mean scores and standard deviations for the Revised IIIness Perception Questionnaire (IPQ-R)

\section{Scores of HRQoL}

As shown in Table 3, patients receiving dialysis showed lower scores on the SF-36 subscales of role-physical (32.5\%) and role-emotional (39.3\%) in comparison to other subscales. In contrast, the best scores were for emotional wellbeing (59.9\%) and social functioning (57.4\%). 


\section{Cureus}

\begin{tabular}{|c|c|c|}
\hline Subscale & Mean & SD \\
\hline Physical functioning & 49.3 & 28.2 \\
\hline Role-physical & 32.5 & 38.4 \\
\hline Role-emotional & 39.3 & 42.9 \\
\hline Energy/fatigue & 43.7 & 20.0 \\
\hline Emotional wellbeing & 59.9 & 21.3 \\
\hline Social functioning & 57.4 & 26.6 \\
\hline Pain & 55.7 & 28.8 \\
\hline General health & 47.9 & 16.1 \\
\hline Health change & 55.8 & 30.4 \\
\hline Total (HRQoL) & 48.2 & 18.8 \\
\hline Subscale & Mean & SD \\
\hline Physical functioning & 49.3 & 28.2 \\
\hline Role-physical & 32.5 & 38.4 \\
\hline Role-emotional & 39.3 & 42.9 \\
\hline Energy/fatigue & 43.7 & 20.0 \\
\hline Emotional wellbeing & 59.9 & 21.3 \\
\hline Social functioning & 57.4 & 26.6 \\
\hline Pain & 55.7 & 28.8 \\
\hline General health & 47.9 & 16.1 \\
\hline Health change & 55.8 & 30.4 \\
\hline il (HRQol & 48. & 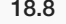 \\
\hline
\end{tabular}

TABLE 3: Mean scores and standard deviations for the SF-36

\section{Impact of illness perceptions on HRQoL}

For all patients receiving dialysis, significant correlations were found between HRQoL and all subscales of the IPQ-R, except for treatment control. However, the correlations of HRQoL with identity, timeline acute/chronic, timeline cyclical, consequences, and emotional representations were negative. In other words, low HRQoL in patients receiving dialysis was associated with a stronger belief in the chronicity and cyclical nature of the illness, that the illness has serious consequences, and that the illness provoked a stronger emotional response.

In contrast, HRQOL was positively correlated with personal control and illness coherence. Thus, stronger beliefs in having a role in managing the illness and a better understanding of the illness were associated with better HRQOL (Table 4). 


\section{Cureus}

\begin{tabular}{|l|ll|}
\hline Subscale & HRQoL & \\
\hline Identity & $\mathrm{R}$ & $\mathrm{P}$ (2-tailed) \\
\hline Timeline acute/chronic & -0.303 & $<.001$ \\
\hline Timeline cyclical & -0.217 & $<.001$ \\
\hline Consequences & -0.296 & $<.001$ \\
\hline Personal control & -0.440 & $<.001$ \\
\hline Treatment control items & 0.191 & $<.001$ \\
\hline IIIness coherence items & 0.063 & 0.248 \\
\hline Emotional representations & 0.320 & $<.001$ \\
\hline
\end{tabular}

TABLE 4: Pearson's correlations between the IPQ-R subscales and SF-36 total score (HRQoL)

\section{Predictors of HRQoL}

Table 5 shows that of the nine independent predictors of IPQ-R subscales, only five contributed significantly to the variance in HRQoL: identity, timeline acute/chronic, consequences, illness coherence, and emotional representations. Illness coherence was a positive predictor while the others were negative predictors. These five factors explained $35 \%$ of the variance in HRQoL.

\begin{tabular}{|c|c|c|c|c|c|}
\hline Independent variable & $\beta$ & SE & Beta & $\mathbf{P}$ & $95 \% \mathrm{Cl}$ for $\beta$ \\
\hline (Constant) & 89.68 & 7.2 & & $<.001$ & $75.48,103.88$ \\
\hline Identity & -.907 & .26 & -.158 & .001 & $-1.427,-.387$ \\
\hline Timeline acute/chronic & -.459 & .17 & -.116 & .011 & $-.811,-.108$ \\
\hline Consequences & -.739 & .21 & -.185 & .001 & $-1.155,-.324$ \\
\hline Illness coherence & 477 & .23 & .101 & .041 & $.019, .934$ \\
\hline Emotional representations & -1.017 & .16 & -.324 & $<.001$ & $-1.346,-.687$ \\
\hline
\end{tabular}

TABLE 5: Regression analysis of IPQ-R subscales predicting SF-36 total score (HRQoL)

In addition, backward regression (Table 6 ) of the demographic factors (sex, age in years, marital status, education level, and occupation) and dialysis characteristics (duration, modality, and center) showed that age, marital status, and dialysis modality were additional independent predictors of the variance in HRQoL. However, together, they explained just $7 \%$ of the variance in HRQoL. 


\section{Cureus}

\begin{tabular}{|c|c|c|c|c|c|}
\hline Independent variable & $\beta$ & SE & Beta & $\mathbf{P}$ & $95 \% \mathrm{Cl}$ for $\beta$ \\
\hline (Constant) & 54.4 & 4.6 & & $<.001$ & $45.399,63.506$ \\
\hline Dialysis modality & 5.3 & 2.5 & .118 & .038 & $.295,10.385$ \\
\hline Age in years & -4.8 & 1.4 & -.186 & .001 & $-7.712,-1.919$ \\
\hline Marital status & -2.7 & 1.0 & -.143 & .012 & $-4.861,-.592$ \\
\hline
\end{tabular}

TABLE 6: Regression analysis of demographic and dialysis factors predicting SF-36 total score (HRQoL)

\section{Discussion}

According to participants' scores on the IPQ-R, participants attributed a low proportion of their symptoms to their illness. They experienced ESRD as a chronic illness that had a negative impact on their lives. Participants were unstable emotionally, though they felt that they could control their illness through their own behavior and treatment. Participants in this study showed an average IPQ-R score, stronger emotional representations, and more symptom variation over time in comparison to patients with other chronic diseases [26,31-35]. Patients with ESRD may experience stronger emotional upset than patients with other illnesses, owing to treatment-related symptoms and the presence of the arterio-venous fistula, which keeps reminding the patients about their need for dialysis [36].

Compared to the general population [28], participants displayed low scores on all subscales of the SF-36. Essentially, this is owing to the burden of the symptoms of their illness and dialysis [37-38]. More importantly, compared to other chronic illnesses, such as chronic gastritis [39] or diabetes mellitus [40], participants reported lower HRQoL in general and greater defects in physical functioning. This might be because patients with ESRD require dialysis on a near-daily basis, with each session lasting for around four or five hours and frequently accompanied by unpleasant symptoms. In addition, potentially treatable symptoms of ESRD are often undertreated [41]. Patients on regular dialysis have reported around nine symptoms (e.g., fatigue, muscle weakness, and sleep difficulty) that resulted in impaired HRQoL [42]. According to another study, the symptom burden of ESRD is similar to that of terminal cancer [43].

The major aim of the current study was to investigate the impact of illness perception on HRQoL. Except for treatment control, all domains of illness perception showed significant correlations with HRQoL. However, the correlations were negative for identity, timeline acute/chronic, timeline cyclical, consequences, and emotional representations. In contrast, personal control and illness coherence showed positive correlations with HRQoL. Accordingly, better HRQoL is associated with a weaker belief in the chronicity and cyclical nature of the illness, perceiving the illness to have serious consequences, and weaker emotional responses. In addition, better HRQoL is associated with a stronger belief in having a role in illness improvement and a better understanding of the illness. This result is consistent with one Malaysian study concerning patients receiving HD [11] and partly with an Iranian study [11]. The latter study showed the same negative correlations but no positive correlations among 120 patients receiving HD.

Five domains of illness perception were independent predictors of the variance in HRQoL: identity, timeline acute/chronic, consequences, illness coherence, and emotional representations. Illness coherence was a positive predictor while the others were negative predictors; together, $35 \%$ of the variance in HRQoL was explained by these five factors. Despite variations between previous studies and this study regarding the names and number of illness perception domains predicting the variance in HRQoL, research is relatively consistent concerning the magnitude of the effects [5,17-18]. The variations in predictors between studies were likely because most studies dealt solely with patients receiving HD. Furthermore, they typically divided HRQoL into the physical component summary and mental component summary subscales; since there is no agreed-upon reference for those components, we instead relied on the approved scoring key.

Emotional representation was the only domain of illness perception that was significantly associated with better HRQoL in both dialysis modalities and in all dialysis centers. Consequently, it can be considered the best predictor of HRQoL, which accords with the findings of previous studies [5,17-18]. Thus, how patients react to their disease or treatment is reflected indirectly in their HRQoL. This follows the SRM, which proposes that patients attempt to reduce their illness in ways that are consistent with their own emotions $[9,44-45]$.

\section{Limitations}

The cross-sectional design of the study was its major limitation, which precluded an assessment of the temporal priority or causality of the observed correlations. Clinical parameters (e.g., hemoglobin level and 


\section{Conclusions}

There was a clear effect of illness perception on HRQoL, with emotional representations being the strongest predictor. Age, marital status, and dialysis modality were additional independent predictors of HRQoL. There is a need for an intervention program to support those patients to improve their quality of life. Further, before beginning an intervention program for patients receiving dialysis, it might be better to explore the effect of illness perception on dialysis treatment. From there, an intervention program could be constructed to target each domain of illness perception in a manner best suited to improving the HRQoL of each patient. Specifically, the emotional response of patients receiving dialysis is the most important domain of illness perception; therefore, it should receive considerable attention in interventions for improving HRQoL. Future studies are required to examine clinical parameters in more detail. A longitudinal design would provide greater detail about the relationship between illness perception and HRQoL.

\section{Additional Information \\ Disclosures}

Human subjects: Consent was obtained or waived by all participants in this study. King Faisal Specialist Hospital and Research Center issued approval RC-J/185/35. Animal subjects: All authors have confirmed that this study did not involve animal subjects or tissue. Conflicts of interest: In compliance with the ICMJE uniform disclosure form, all authors declare the following: Payment/services info: All authors have declared that no financial support was received from any organization for the submitted work. Financial relationships: All authors have declared that they have no financial relationships at present or within the previous three years with any organizations that might have an interest in the submitted work. Other relationships: All authors have declared that there are no other relationships or activities that could appear to have influenced the submitted work.

\section{References}

1. Culleton BF, Asola MR: The impact of short daily and nocturnal hemodialysis on quality of life, cardiovascular risk and survival. J Nephrol. 2011, 24:405-15. 10.5301/JN.2011.8422

2. Jha V, Garcia-Garcia G, Iseki K, et al.: Chronic kidney disease: global dimension and perspectives . Lancet. 2013, 382:260-72. 10.1016/S0140-6736(13)60687-X

3. Radic J, Ljutic D, Radic M, Kovacic V, Sain M, Curkovic KD: The possible impact of dialysis modality on cognitive function in chronic dialysis patients. Neth J Med. 2010, 68:153-57.

4. Finnegan-John J, Thomas VJ: The psychosocial experience of patients with end-stage renal disease and its impact on quality of life: findings from a needs assessment to shape a service. ISRN Nephrol. 2013, 2013:308986. 10.5402/2013/308986

5. Timmers L, Thong M, Dekker FW, et al.: Illness perceptions in dialysis patients and their association with quality of life. Psychol Health. 2008, 23:679-90. 10.1080/14768320701246535

6. Bapat U, Kedlaya PG: Perceived illness intrusion among patients on hemodialysis. Saudi J Kidney Dis Transpl. 2009, 20:386-91.

7. O'Connor SM, Jardine AG, Millar K: The prediction of self-care behaviors in end-stage renal disease patients using Leventhal's Self-Regulatory Model. J Psychosom Res. 2008, 65:191-200. 10.1016/j.jpsychores.2008.02.008

8. A self-regulation model of depression: content of cognitive representations and prediction of treatment seeking. (2011). Accessed: July 14, 2020: https://ir.lib.uwo.ca/etd/328/.

9. Tasmoc A, Hogas S, Covic A: A longitudinal study on illness perceptions in hemodialysis patients: changes over time. Arch Med Sci. 2013, 9:831-6. 10.5114/aoms.2013.38678

10. Harvey JN, Lawson VL: The importance of health belief models in determining self-care behaviour in diabetes. Diabet Med. 2009, 26:5-13. 10.1111/j.1464-5491.2008.02628.x

11. Kim Y, Evangelista LS: Relationship between illness perceptions, treatment adherence, and clinical outcomes in patients on maintenance hemodialysis. Nephrol Nurs J. 2010, 37:271-81.

12. Ayoub AM, Hijjazi KH: Quality of life in dialysis patients from the United Arab Emirates . J Family Community Med. 2013, 20:106-12. 10.4103/2230-8229.114772

13. Kim JY, Kim B, Park KS, et al.: Health-related quality of life with KDQOL-36 and its association with selfefficacy and treatment satisfaction in Korean dialysis patients. Qual Life Res. 2013, 22:753-8. 10.1007/s11136-012-0203-X

14. Østhus TB, Preljevic VT, Sandvik L, Leivestad T, Nordhus IH, Dammen T, Os I: Mortality and health-related quality of life in prevalent dialysis patients: comparison between 12-items and 36-items short-form health survey. Health Qual Life Outcomes. 2012, 10:46. 10.1186/1477-7525-10-46

15. Theofilou P: Quality of life in patients undergoing hemodialysis or peritoneal dialysis treatment . J Clin Med Res. 2011, 3:132-8. 10.4021/jocmr552w

16. Shiao CC, Kao TW, Hung KY, et al.: Seven-year follow-up of peritoneal dialysis patients in Taiwan . Perit Dial Int. 2009, 29:450-7. 10.1177/089686080902900412

17. Covic A, Seica A, Gusbeth-Tatomir P, Gavrilovici O, Goldsmith DJ: Illness representations and quality of life scores in haemodialysis patients. Nephrol Dial Transplant. 2004, 19:2078-83. 10.1093/ndt/gfh254

18. Mollaoglu M, Candan F, Mollaoglu M: Illness perception and hopelessness in hemodialysis . Arch Clin Nephrol. 2016, 2:044-8.

19. Al-Sayyari AA, Shaheen FA: End stage chronic kidney disease in Saudi Arabia. A rapidly changing scene . Saudi Med J. 2011, 32:339-46. Accessed: October 18, 2020: https://pubmed.ncbi.nlm.nih.gov/21483990/. 
20. Hejaili FF, Tamim H, Ghamdi GA, et al.: Level of health awareness of Saudi patients on renal replacement therapy. Saudi Med J. 2007, 28:747-51.

21. Saudi Center for Organ Transplantation (SCOT). Annual report for organ transplantation in Kingdom of Saudi Arabia. (2017). Accessed: October 13, 2020: http://www.scot.gov.sa/webb/Reports/1034.

22. Moss-Morris R, Weinman J, Petrie KJ, Horne R, Cameron LD, Buick D: The revised illness perception questionnaire (IPQ-R). Psychol Health. 2002, 17:1-16. 10.1080/08870440290001494

23. Hays RD, Morales LS: The RAND-36 measure of health-related quality of life . Ann Med. 2001, 33:350-7. 10.3109/07853890109002089

24. Brzoska P, Yilmaz-Aslan Y, Sultanoglu E, Sultanoglu B, Razum O: The factor structure of the Turkish version of the Revised Illness Perception Questionnaire (IPQ-R) in patients with diabetes and cardiovascular disease. BMC Public Health. 2012, 12:852. 10.1186/1471-2458-12-852

25. Hill S: The Illness Perceptions Questionnaire-Revised (IPQ-R) . J Physiother. 2010, 56:280. 10.1016/S18369553(10)70062-X

26. Bijsterbosch J, Scharloo M, Visser AW, et al.: Illness perceptions in patients with osteoarthritis: change over time and association with disability. Arthritis Rheum. 2009, 61:1054-61. 10.1002/art.24674

27. Das LT, Wagner CD, Bigatti SM: Illness representations of cancer among healthy residents of Kolkata, India . Asian Pac J Cancer Prev. 2015, 16:845-52. 10.7314/APJCP.2015.16.2.845

28. Coons SJ, Alabdulmohsin SA, Draugalis JR, Hays RD: Reliability of an Arabic version of the RAND-36 Health Survey and its equivalence to the US-English version. Med Care. 1998, 36:428-32. 10.1097/00005650199803000-00018

29. RAND: 36-Item Short Form Survey from the RAND Medical Outcomes Study . Accessed: September 12, 2020: http://www.rand.org/health/surveys_tools/mos/mos_core_36item.html.

30. Osborne J, Waters E: Four assumptions of multiple regression that researchers should always test . Prac Assess Res Eval. 2002, 8:2. 10.7275/r222-hv23

31. Ziarko M, Mojs E, Piasecki B, Samborski W: The mediating role of dysfunctional coping in the relationship between beliefs about the disease and the level of depression in patients with rheumatoid arthritis. Sci World J. 2014, 2014:585063. 10.1155/2014/585063

32. Morgan K, Villiers-Tuthill A, Barker M, McGee H: The contribution of illness perception to psychological distress in heart failure patients. BMC Psychol. 2014, 2:50. 10.1186/s40359-014-0050-3

33. Grayson PC, Amudala NA, Mcalear CA, et al.: Illness perceptions and fatigue in systemic vasculitis . Arthritis Care Res (Hoboken). 2013, 65:1835-43. 10.1002/acr.22069

34. Sawicki GS, Sellers DE, Robinson WM: Associations between illness perceptions and health-related quality of life in adults with cystic fibrosis. J Psychosom Res. 2011, 70:161-7. 10.1016/j.jpsychores.2010.06.005

35. Jablonski A: The multidimensional characteristics of symptoms reported by patients on hemodialysis . Nephrol Nurs J. 2007, 34:29-37; quiz 38.

36. Merighi JR, Ehlebracht K: Issues for renal social workers in dialysis clinics in the United States. A survey/Part II. Nephrol News Issues. 2004, 18:67-8, 71-5.

37. O'Connor NR, Corcoran AM: End-stage renal disease: symptom management and advance care planning . Am Fam Physician. 2012, 85:705-10.

38. Merkus MP, Jager KJ, Dekker FW, de Haan RJ, Boeschoten EW, Krediet RT: Physical symptoms and quality of life in patients on chronic dialysis: results of The Netherlands Cooperative Study on Adequacy of Dialysis (NECOSAD). Nephrol Dial Transplant. 1999, 14:1163-70. 10.1093/ndt/14.5.1163

39. Wen Z, Li X, Lu Q, et al.: Health related quality of life in patients with chronic gastritis and peptic ulcer and factors with impact: a longitudinal study. BMC Gastroenterol. 2014, 14:149. 10.1186/1471-230X-14-149

40. Faria HT, Veras VS, Xavier AT, Teixeira CR, Zanetti ML, Santos MA: Quality of life in patients with diabetes mellitus before and after their participation in an educational program [Article in Portuguese]. Rev Esc Enferm USP. 2013, 47:348-54. 10.1590/s0080-62342013000200011

41. Claxton RN, Blackhall L, Weisbord SD, Holley JL: Undertreatment of symptoms in patients on maintenance hemodialysis. J Pain Symptom Manage. 2010, 39:211-8. 10.1016/j.jpainsymman.2009.07.003

42. Yong DS, Kwok AO, Wong DM, Suen MH, Chen WT, Tse DM: Symptom burden and quality of life in endstage renal disease: a study of 179 patients on dialysis and palliative care. Palliat Med. 2009, 23:111-9. $10.1177 / 0269216308101099$

43. Saini T, Murtagh FE, Dupont PJ, McKinnon PM, Hatfield P, Saunders Y: Comparative pilot study of symptoms and quality of life in cancer patients and patients with end stage renal disease. Palliat Med. 2006, 20:631-6. 10.1177/0269216306070236

44. Fowler C, Baas LS: Illness representations in patients with chronic kidney disease on maintenance hemodialysis. Nephrol Nurs J. 2006, 33:173-4, 179-86. Accessed: April 12, 2020: https://pubmed.ncbi.nlm.nih.gov/16613412/.

45. Lobchuk MM, McClement SE, McPherson CJ, Cheang M: Impact of patient smoking behavior on empathic helping by family caregivers in lung cancer. Oncol Nurs Forum. 2012, 39:E112-21. 10.1188/12.ONF.E112E121 